Referencia para citar este artículo: Sánchez-Jiménez, M. H. (2017). Prácticas dialógicas y códigos sociolingüísticos: crisis y cambios familiares en contextos dialógicos. Revista Latinoamericana de Ciencias Sociales, Niñez y Juventud, 15 (2), pp. 1179-1190. DOI:10.11600/1692715x.1522615122016

\title{
Prácticas dialógicas y códigos sociolingüísticos: crisis y cambios familiares en contextos dialógicos*
}

\author{
MARÍA HILDA SÁNCHEZ-JIMÉNEZ ** \\ Profesora Titular Universidad de Caldas, Colombia.
}

\begin{abstract}
Artículo recibido en diciembre 15 de 2016; artículo aceptado en marzo 30 de 2017 (Eds.)
\end{abstract}
- Resumen (analítico): el presente artículo responde al objetivo central de la investigación de "comprender y explicar las prácticas dialógicas y los códigos sociolingüísticos que han utilizado las familias durante el proceso de superación de situaciones de crisis". Es un estudio cualitativo y hermenéutico, apoyado en los criterios de la Grounded Theoryy en las perspectivas sistémica y socio construccionista. Los testimonios fueron dados por integrantes de 30 familias de los municipios de Manizales, Neira y Risaralda que accedieron voluntariamente a presentar su experiencia. Se concluye que en los movimientos entre la crisis y el cambio hay quiebres en la organización y el funcionamiento familiar, desnaturalización de patrones interaccionales, reconocimientos, aprendizajes personales y sociofamiliares, y la exaltación de los procesos de crisis como potencial para ver aquello que no se debe repetir en sus vidas.

Palabras clave autora: crisis sociofamiliar, prácticas dialógicas, códigos sociolingüísticos, contextos, cambios.

\section{Dialogical Practices and Sociolinguistic Codes: Crisis and Family Changes in Dialogical Contexts}

- Abstract (analytical): this article responds to the main objective of the research study that it describes: understand and explain the dialogical practices and the sociolinguistic codes used by families during the process of overcoming crisis situations. It is a qualitative hermeneutic study that uses the criteria of Grounded Theory and systemic and social constructionist perspectives. The testimonies were provided by members of 30 families from the municipalities of Manizales, Neira and Risaralda who voluntarily agreed to share their own experiences. It is concluded that in the transition between the crisis and subsequent change there are breakdowns in the functioning of the family and its organization, a denormalization of interaction, recognition and personal patterns, ruptures in socio-family learning and a valuing of the crisis process as having the potential to help them identify what should not be repeated in their lives.

Este artículo de investigación, científica y tecnológica presenta los resultados del proyecto de investigación denominado "Prácticas dialógicas y códigos sociolingüísticos en familias hacia la superación de situaciones de crisis", financiado por la Universidad de Caldas, inscrito en septiembre de 2014 en la Vicerrectoría de Investigaciones y Postgrados con el código: 1521414. Realizada entre el 15 de septiembre de 2014 y el 15 de diciembre de 2016. El artículo se inscribe en las ciencias sociales, subárea: Estudios de Familia.

** Psicóloga de la Universidad de Manizales, Magister en Psicología Clínica y de Familia de la Universidad Santo Tomás de Aquino, Doctora en Psicología de la Universidad de Buenos Aires. Profesora titular del Departamento de Estudios de Familia, Facultad de Ciencias Jurídicas y Sociales, Universidad de Caldas. Manizales, Colombia. Orcid: 0000-0001-8142-1779. Índice H5: 2. Correo electrónico: maria.sanchez_j@ ucaldas.edu.co 
Authors' key words: socio-familiar crisis, dialogical practices, sociolinguistic codes, contexts, changes.

\section{Práticas dialógicas e códigos sociolinguísticos: crise familiar e alterações nos contextos dialógicos}

- Resumo (analítico): este artigo responde ao objetivo central da pesquisa: compreender e explicar as práticas dialógicas e códigos sociolinguísticos utilizado por famílias durante o processo de superação de situações de crise. É um estudo qualitativo e hermenéutico apoiado pelos critérios da o Grounded Theory nas perspectivas sistémica e socio-construtivista. Os testemunhos foram dados por membros de 30 familias nos municípios de Manizales, Risaralda e Neira, que voluntariamente concordaram em apresentar a sua experiência. Conclui-se que os movimentos entre a crise e a mudança apresentam rupturas na organização e funcionamento familiar, a desnaturalização dos padrões interacionais, o reconhecimento, a aprendizagem pessoal e socio-familiar, e a exaltação dos processos de crise como o potencial para ver aquilo que não debe ser repetido na vida.

Palavras chave do autor: crise socio-familiar, práticas dialógicas, códigos sociolinguísticos, contextos, mudanças.

-1. Introducción. -2. Problema de la investigación. -3. Proceso metodológico. -4. Referente teórico. -5. Resultados. -6. Conclusiones. -Lista de referencias.

\section{Introducción}

El artículo se centra en uno de los objetivos de la investigación: "identificar, desde las prácticas dialógicas y los códigos sociolingüísticos, los recursos, las estrategias y las fortalezas sociofamiliares que han permitido afrontar y resolver situaciones de crisis". Si bien la partida está en las voces creadas en el momento testimonial, el preámbulo fue la trama sobre la situación de crisis elegida, de manera voluntaria, por uno o varios integrantes de cada familia y bajo la premisa de que fuera reconocida por ellos como "una situación superada de manera satisfactoria". Este texto se mueve entre dos momentos centrales de cada experiencia familiar: una, el surgimiento de una situación de crisis $\mathrm{y}$, dos, la búsqueda de cambios o transformaciones a la misma.

Entre uno y otro momento, la situación de crisis tuvo un fuerte impacto en la vida de los integrantes de las familias. A su paso por cada escena, las personas expresaron diversas formas de afectaciones emocionales, cognitivas o biológicas con alto impacto relacional, especialmente en sus familias de origen. También aparece la mirada desde donde se cruzó el dolor de lo vivido, el reto de una lucha por lograr transformar la crisis en oportunidad para seguir adelante y emprender otras formas de vida. "Cada testimonio da cuenta de una memoria traumática, compartida, en la historia de vida que se ofrece al investigador como rasgo emblemático de lo social" (Arfuch, 2013, p. 20).

Lo anterior, se ve reflejado en lo que sigue en este texto, cuyas reflexiones están soportadas en fragmentos cortos de algunas historias ${ }^{1}$ que son parte de la investigación de donde se derivó este artículo. Del interés por resolver la pregunta por la forma como las familias perciben el proceso de superación de las crisis, sus narraciones y traducciones de cada momento de la trama, unidas a la interpretación como investigadora, emergieron diversas categorías, de las cuales en este artículo se presentan: la crisis como evento sorpresa, los quiebres sociofamiliares y problemas derivados, la desnaturalización de patrones interactivos y la búsqueda de salidas, decisiones y cambios.

\section{El problema de la investigación}

En mi estudio anterior a esta investigación, titulado: códigos sociolingüísticos, familias y

1 A cada fragmento tomado de cinco historias, le antecede una viñeta con el fin de ilustrar al lector el eje temático sobre el que giró la narración. 
terapia familiar sistémica. Procesos de cambio sociofamiliar, cité que: desde la perspectiva sistémica y la construccionista social, terapeutas e investigadores inquietos por los procesos que generan cambio en el contexto de la terapia se han preguntado: ¿qué ocurre cuando se desorganiza el aprender a aprender? (Bateson, 2006); ¿qué coordinaciones discursivas y sociales producen el cambio?, ¿qué herramientas y recursos promovieron los procesos de cambio y las nuevas posibilidades? (Fried-Schnitman, 2008, 2010); ¿cuál es la función de la reconstrucción narrativa?, ¿cómo podemos desplazar el diálogo en dirección al cambio? (Gergen, 1996, 2007); ¿cómo logramos este diálogo generativo, colaborativo, igualitario, donde el cliente es el experto? (Anderson, 1999).

No obstante, en la presente investigación, de donde se deriva este artículo, la pregunta no está centrada en los procesos terapéuticos, sino en las familias como agencia de cambio $\mathrm{y}$ transformación de sus conflictos. Una indagación que abre un panorama que visibiliza lo novedoso en las dinámicas familiares, los recursos, las estrategias, las fortalezas, las decisiones y acciones realizadas por diversos actores sociales que resultaron acertadas y favorables al cambio. De ahí la pregunta por ¿cuáles son las prácticas dialógicas y los códigos sociolingüísticos que co-construyen los grupos familiares para generar procesos de cambio ante situaciones de crisis?

\section{Proceso metodológico}

La investigación fue cualitativa, con un enfoque hermenéutico que guió en el marco de las prácticas dialógicas y los códigos sociolingüísticos, la construcción del significado y el sentido de las narraciones sobre las crisis y los procesos de cambio. Este enfoque ayudó a captar y reconstruir: a) las construcciones dialógicas y relacionales creadas entre los integrantes de las familias, b) las acciones, las estrategias, los recursos y las fortalezas que ayudaron al logro del cambio o la transformación de una situación de crisis, d) los enlaces sociolingüísticos o patrones de interacción recurrentes en las historias, e) los significados y los sentidos en contexto que emergieron, f) el proceso y los apoyos que vivieron las personas para hoy considerar que la crisis ha sido superada.

El procedimiento metodológico estuvo basado en los criterios de la Grounded Theory (Strauss \& Corbin, 2002): a) "el método de la comparación constante", por semejanzas y diferencias en las situaciones de crisis identificadas; y b) "el muestreo teórico", con el fin de refinar o expandir los conceptos y teorías ya desarrolladas, y tener una mayor comprensión teórica sobre el tema de la investigación. De forma simultánea, se logró el planteamiento y desarrollo de conceptos centrales que fueron enriquecidos en el proceso de categorización y ajuste.

Con el fin de garantizar validez $y$ confiabilidad a los resultados se recibieron los testimonios de integrantes de 30 familias de tres (3) Municipios del Departamento de Caldas: 10 de Manizales, 10 de Neira y 10 de Risaralda. Cada familia definió previamente la situación a narrar y la persona o las personas que participarían como narradores de la historia. Lo único previsto para este momento fue que aquella o aquel que brindara la información tuviera 18 o más años de edad, debido a la delicadeza del contenido en los fragmentos de cada historia y por el consentimiento de la grabación en audio y video.

\section{Referente teórico}

\section{Prácticas dialógicas y códigos sociolingüísticos}

Ambos conceptos, prácticas dialógicas y códigos sociolingüísticos, se enmarcan en los campos de las ciencias sociales, la sociolingüística y las prácticas psicosociales. Contienen perspectivas de abordajes epistemológicos, teóricos y metodológicos que, en sus trabajos investigativos, reflexivos $\mathrm{y}$ de intervención integran planteamientos, especialmente, de las perspectivas: sistémica, construccionista social y filosofía del lenguaje. Más aún, son construcciones complejas cuyo foco de atención es lo dialógico y lo relacional, desde donde las personas en interacción producen acciones creativas para afrontar 
situaciones difíciles en sus vidas, tal como puede verse en aquello que comúnmente es denominado momentos de crisis.

Las prácticas dialógicas y los códigos sociolingüísticos son formas de lenguajes que utilizan diversas comunidades sociales, con el fin de expresar algo sobre algo o alguien. Ambas se co-construyen en la interacción humana y están presentes en los diálogos entre hablantes cuando intercambian diversas ideas sobre asuntos comunes o diferentes, cuyas expresiones verbales y no verbales contienen las voces creadas en la historia de vida de cada hablante. Al estar presentes en las formas de lenguaje y de vida de los sujetos, las prácticas dialógicas y los códigos sociolingüísticos acompañan las conversaciones y los diálogos externos e internos de las personas para crear significados, cuya interpretación sólo es posible en un contexto interactivo articulado a las formas de vida del ser humano y de su forma de expresar. Como dice Wittgenstein (2007), las expresiones tienen relación con la localización corporal, es decir, lo que tiene que ver con el impacto fisiológico de la expresión. En este sentido, las palabras unidas a la expresión del rostro humano son significativas y orienta los significados y los sentidos de lo que es recordado y la manera como se recuerda.

Las prácticas dialógicas como los códigos $^{2}$ son formas de lenguajes, conexiones sociolingüísticas entre los hablantes que regulan las interacciones y reflejan patrones relacionales, cuyas características están ligadas al contexto interactivo co-construido por las

2 Por ejemplo, Sánchez-Jiménez $(2013,2015,2016)$ presenta que en las conversaciones emergen señales sociolingüísticas o códigos creados por personas, parejas, familias, terapeutas, etcétera., en las que se construyen pautas de interacción particulares, según el momento conversacional en el cual estén los hablantes: Estos códigos y su significado son los siguientes: 1) contexto: explora y evalúa los significados y los sentidos verbales y no verbales; 2 ) contrastación: confronta las diversas voces y situaciones dialógicas; 3) rebote: diálogos que llevan connotaciones negativas que pueden provocar una escalada simétrica; 4) circular perceptivo:envuelve una secuencia de acciones/re-acciones/relaciones entre dos o más personas implicadas en el evento; 5) suspensión: interrumpe una pauta narrativa mediante giros sociolingüísticos como cambiar de foco temático o de hablante; 6) reconocimiento: enaltece a las personas como interlocutoras válidas y crea connotaciones positivas; 7) complemento: expresan acuerdos en medio de un contexto más colaborativo; 8) imaginativo: alienta a la creatividad $\mathrm{y}$, por consiguiente, estimula la planeación y ejecución de proyectos de vida y nuevas formas de enfrentar los conflictos; y 9) integrativo: reconoce las redes de apoyo intra y extrafamiliares. personas. Los códigos que acompañan las prácticas dialógicas de los hablantes son el resultado de un aprendizaje que adquiere todo sistema humano en sus relaciones familiares y sociales $\mathrm{y}$, en este ámbito, tienen la posibilidad de transformarse. Cuando en una práctica dialógica prima una forma de código para acompañar y regular las relaciones, esta forma sociolingüística puede mantener o transformar las experiencias cotidianas de los sujetos dentro del sistema familiar (Sánchez-Jiménez, 2013, 2015, 2016; Patiño-López, 2017).

En este marco epistemológico, la creación de significado, la experiencia y el conocimiento son procesos constructivos con capacidad potencial de transformar las pautas de relación social entre las personas. Desde la diversidad de diálogos, la creatividad y las oportunidades dialógicas cada quien explora la emergencia de alternativas para salir de los conflictos y problemas, la creación de nuevas formas de relación hacia soluciones satisfactorias, las innovaciones y el reconocimiento de los recursos que transforman tanto las conversaciones como a quienes participan en el proceso (FriedSchnitman, 2008). Es decir, el cambio emerge cuando las personas obran desde la creatividad, el reconocimiento, la integración de diálogos, las oportunidades para co-construir nuevos contextos y nuevos proyectos de vida tanto personales como familiares.

Bajtín plantea que los diálogos son tan amplios, múltiples, diversos y complejos que no puede haber un plano único para su estudio. La diversidad de ellos depende de su tema, situación y participante. Van en la combinación de voces propias y ajenas, lo que se construye entre el yo y lo otro, en lo que da identidad a las personas (Bajtín, 1997, 2000, 2011; Bubnova, 2006; García, 2012). Por lo tanto, es en el diálogo donde la identidad de las personas y sus relaciones se construyen, permanecen o se transforman.

\section{Resultados}

\section{La crisis como evento sorpresa}

El hecho de que las personas escojan una situación de crisis y no otra para ser narrada, 
para recordar el proceso y la forma como fue afrontada, permite que dicha situación y su historia sea considerada un evento, uno entre muchas otras situaciones. Es un evento, por cuanto deja una huella significativa en la vida de las personas que ha implicado tiempos prolongados de sufrimiento, dolor, terror, angustia, tensión y tristezas. El evento deja una huella, a tal punto que al ser puesto en la historia recordada y narrada conlleva a revivir en el presente, aunque de forma diferente, los sentimientos, las emociones, las sensaciones y las acciones pasadas. Por ello, un evento es visto como irrepetible o como lo que no quiere volverse a vivir: "Fue algo como extraordinario, o sea, se volvió algo que yo diría si me tocara volver a repetirlo no, yo diría que no habría como" (Padre, 44 años, Manizales); "yo pienso que a mí no me volvería a pasar... Ya no se puede repetir" (Hija, 21 años, Manizales); "estar como dice el cuento: tener paz en el corazón" (Hermana, 23 años, Risaralda).

Cuando alguien hace referencia a un evento habla de algo sorpresivo y novedoso, que lleva consigo una paradoja experiencial. Es decir, contiene dos caras, una positiva y otra negativa. Uno, por ser una manera de rehacer algo en sus vidas $\mathrm{y}$, dos, porque hubo la presencia de daños a la integridad de las personas y familias.

Cuando es visto como positivo, el evento es asociado a momentos percibidos como favorables para las personas o las familias, a una nueva construcción de significados y sentidos asociados al cambio. Cuando las personas perciben el evento como negativo, lo significan como la agudización de una situación problemática inesperada, para algunos único e irrepetible, que afecta a quienes estuvieron relacionados con el evento y con las personas que lo vivieron directamente. En este último caso, el evento queda asociado a la palabra "crisis" o como aparece en algunos testimonios, a: algo "terrible", "horroroso", "traumático", "muy doloroso", "crítico", "tensa", entre otras afirmaciones.

En ambos casos, las dinámicas relacionales son afectadas, porque emergieron coordinaciones liberadoras para las personas, se fortalecieron momentos de unión o solidaridad como ocurrió con algunas familias, o porque las personas se enfrentaron a una lucha entre lo que sucede y el alcance de sus capacidades para seguir adelante o sobrevivir. Por ejemplo,

Madre separada, encargada del sostenimiento y crianza de sus dos hijos de 9 y 5 años, secuestrada por un frente de la guerrilla. "Felizmente sali muy favorable de todo eseproceso, mis hijos también, mifamilia también, por supuesto. Son situaciones que afectan todo el entorno, los amigos, el trabajo (...) Como profesional, que ya logré votar todo ese dolor... El dolor sí tiene que ir saliendo porque uno tiene que irlo sacando, porque es de la única manera que uno perdona y vuelve a vivir una situación de calma, de volver a vivir oportunidades como lo he hecho... dejar salir el dolor, dejarlo, evaluarlo y si hay algo que sanar pues encausar. Por ejemplo, yo me pude salir y encausé y no me fue mal... No hay que huirle a los problemas, no hay que salir corriendo. Saber qué fortalezas y qué debilidades hay y como mejoro mi vida" (Madre, 50 años, Neira).

Afrontamiento familiar del proceso de cáncer y muerte del hijo de 2 años y medio. Impotencia frente al tratamiento, los trámites y procesos médicos y hospitalarios.

"Fue algo como extraordinario, o sea, se volvió algo que yo diría que si me tocara volver a repetirlo no. Yo diría que no habría como. O sea, yo consideré que fue un acto de heroísmo frente esas cosas. No, no por el evento en sí, sino por la relación y la vivencia ¿cierto? Si uno se pone a revisar eso, ¡uy!, yo no me enloquecí (...) También es parte del aprendizaje y saber sortear y sacar lo mejor siempre de lo que llegue, porque eso es lo que le queda a uno, la posibilidad de aprovechar, de trabajar con lo que hay en el momento, de aprovechar uno a las personas, a las personas que tiene cerca, de aprender de ellas en sus diferencias..." (Madre, 40 años; Padre, 44 años, Manizales).

Desplazamiento forzado por parte de un grupo de las autodefensas de Colombia, rechazo 
por parte de otras poblaciones y discriminación racial hacia los hijos en la escuela.

"Hace 17 años yo fui desplazada de Urabá con mi papá, mi mamá y siete hermanos. Llegamos a un pueblo que se llamaba Supía Caldas. Ahi llegamos prácticamente desplazados y nos tocó vivir un tiempo muy crítico, muy duro, de necesidades, hambres, etc., muchas cosas (...) Transcurrieron por ahi algunos siete, ocho años que ya nos empezó a cambiar un poquito la suerte (...) Sinceramente, como le decía anteriormente, yo le doy gracias a Dios que me iluminó con la llegada por acá, porque primero que todo, yo creo que o esta niña estuviera muerta o estuviera embarazada, o no estuviera conmigo. Me la hubieran... Estuviera en una cárcel" (Madre, 45 años, Risaralda).

Una situación de crisis representa un quiebre en el transcurrir de la vida cotidiana de las personas y las familias, y es un referente de cambio porque marcó nuevas dinámicas relacionales y movimientos en el funcionamiento y la organización del sistema familiar. Las crisis están estrechamente relacionadas con el cambio. Por un lado, surgen cambios inesperados: alteraciones físicas, emocionales y cuidados; muerte por enfermedad; intento de homicidio; desapariciones; desplazamientos; salidas de las personas del hogar por amenazas o tensiones relacionales en la familia; llegada inesperada y no deseada de una persona al sistema familiar, etcétera.

Por otro lado, los cambios en la familia son evidentes mediante la emergencia de situaciones colaterales caracterizadas por comportamientos y relaciones que estaban como telón de fondo: consumo de sustancias psicoactivas, problemas con la ley, patrones de violencia sociofamiliar, coaliciones, conflictos de pareja, rivalidades fraternales o materno-paterno filiales. "La crisis es a la vez reveladora de aquello que permanece oculto en las épocas ordinarias y efectora de procesos de transformación" (Hernández, 2004, p. 101).

Cuando aparece la crisis como un evento sorpresivo, las expectativas creadas se derrumban y es co-construido un contexto caracterizado por el desconcierto, la angustia, el temor y la alteración de transacciones sociofamiliares. Se une la sensación de impotencia y desorden frente a la pregunta en torno a cuál puede ser la mejor manera de salir de la encrucijada, quiénes actuarán, de qué manera, cuándo, con quién, y a la vez emergen los juicios, señalamientos, culpas y calificativos más caracterizados por lo negativo. Es decir, el problema está a flor de piel y por ello los códigos o las señales sociolingüísticas de contrastación, rebote y circular perceptivo con connotaciones negativas, para sí mismo y para los demás, son evidentes: "todos los días llegaban a pelear por eso, que por culpa de ella estaban así y que por culpa de ella habían perdido lo que tenían" (hija, 21 años. Manizales).

El mundo que encierra una crisis en las familias es complejo y caótico, porque las huellas que deja a su paso traspasa cada vínculo, lo fragmenta y hay que rehacerlo para volver a reconfigurar y resignificar múltiples dimensiones de la vida sociofamiliar -psicológica/emocional, biológica/física, cognitiva, social, económica, territorial, temporal, cultural e histórica. Son múltiples los movimientos y ensayos que deben realizar las personas y sus familias como también los errores a afrontar y superar. Las acciones son extenuantes, al punto de llegar a límites entre los integrantes de las familias, tales como separaciones, enfrentamientos hostiles física o verbalmente, pautas relacionales violentas en las familias. En fin, se crean quiebres en las relaciones familiares

\section{Quiebres en las relaciones familiares y problemas múltiples}

Es importante destacar que en las familias con una historia relacional con permanentes disgustos, enfrentamientos entre sus integrantes, problemas de diversa índole entre uno u otro miembro de la familia, el proceso de afrontamiento es complejo debido a la dispersión creada por los múltiples focos problemáticos que deben ser atendidos. Por lo tanto, el logro de las salidas, la solución o la transformación de los conflictos está caracterizado por estar sobre una plataforma conflictiva, de confrontación y 
rebote entre las partes, hasta crear relaciones en escaladas simétricas. Cada vez es más alto el nivel de tensión y presión entre los integrantes de las familias y su entorno.

Las partes en el conflicto se descalifican, juzgan y culpabilizan mutuamente y, como bola de nieve, se acrecienta el proceso de separación, dolor, rabia y frustración por lo que pudo haber sido y no fue, como por el abismo creado para volver a recuperar la unión afectada en las relaciones familiares.

Muerte del padre en la familia $y$ surgimientos de diversos problemas con la madre y los hermanos, caracterizados por pautas relacionales violentas y consumo de SPA.

"Yo me salí de la casa, dejé de vivir con mi mamá cuando tenía 12. Pero me fui a vivir con una hermana... Entonces, yo, ya veía a mi mamá los fines de semana, o de pronto me quedaba ahi en Manizales donde mi otra hermana... Cuando tenía como los 18 o 19 años volvi donde mi mamá... Y al vivir acá en Neira con ella, me consiguió trabajo en otra cafetería acá. Ya, de nuevo los problemas (...) Entonces, le digo yo a mamá que: mire las cosas siguen igual, él [hermano] igual pegándome... Entonces, una vez, yo le dije unas cosas muy feas a mi hermano, lo insulté muy feo la verdad. Entonces, mi mamá estaba ahí y le dio mucha rabia (...) Entonces, mi mamá me dijo, me respondió: si alguien se tiene que ir es usted (...) Entonces, yo me fui. Y es algo que mi mamá aun me reprocha" (Hija, 26 años, Neira).

Teniendo presente que un evento de crisis tiene efectos colaterales, en tanto impulsa el surgimiento de otros problemas que no eran evidentes o se mantenía como telón de fondo, las personas quedan enfrentadas a solucionar aquello que más le afecta directamente. Se crea un contexto familiar multiproblemático que demanda otras acciones imprevistas y cada vez más complejas. Por ejemplo, la "Muerte del padre en la familia y surgimientos de diversos problemas con la madre y los hermanos, caracterizados por pautas relacionales violentas y consumo de SPA" (Hija, 26 años, Neira); "Secuestro y asesinato de una cuñada por paramilitares, seguido de desplazamiento, pérdidas económicas, enfermedad postraumática del marido (obesidad y Depresión) y muerte" (Esposa y Madre, 55 años, Risaralda). Una nueva situación relacional abre otro enfoque del problema que también debe ser atendido y, así sucesivamente.

Por ello la acción ante el peligro como manera de proteger la integridad emocional o física de una persona, está asociada a los procesos de afrontamiento y también a la posibilidad de abrir otros focos problemáticos que ameritan ser atendidos. Si las personas que tienen vínculos familiares conflictivos no cierran el ciclo del problema de manera clara, ni reconocen su posición frente a los demás, ni los límites de sus decisiones, la salida que tomen tendrá un carácter no triunfal. La plataforma relacional que sostiene los patrones de interacción porta una especie de embotellamiento en donde pueden quedar atrapadas las nuevas relaciones $y$, entonces, la historia y sus narrativas interactivas se repiten con los nuevos actores con quienes fue vista una forma de escapatoria. Por ejemplo, "embarazo de la hija a los 17 años y la salida del hogar y posterior vivencia de una relación conyugal con pautas interaccionales violentas (Madre, 48 años; hija, 21 años, Manizales). Estas acciones son articuladas dentro de los patrones de interacción y perpetúan la historia relacional confusa y generadora de incertidumbres.

En el sistema familiar, como parte del proceso de afrontamiento, se crean alianzas especialmente con la persona percibida como vulnerada o víctima del otro o la otra. A su paso, emergen separaciones en algunas relaciones. Por ejemplo,

Mujer con más de 30 años de casada decide terminar su relación con su esposo, después de tres años de infidelidad por parte de él y de luchar por conservar la relación y el hogar.

"E: - Y, su hijo, ¿no sabía todavía?

-No, él estaba por fuera. Cuando un día, ya él empezó a notar que nosotros [ella y el esposo] ya nada, de nada, pero no decía nada (...) Yo le saqué café y por no hablarle me fui hasta la puerta y dijo: yo no quiero... Entonces, me dijo: yo ya almorcé arriba en la finca antes de 
venirme, pero yo no sabía que Omar se había entrado por aquí y, estaba en la otra pieza... Cuando sale Omar: Eso no le ruegue, si no le quiere recibir, no le ruegue, es que usted también. [Dirigiéndose al padre], ¿cuál es la pendejada?, que usted tiene a mi mamá como de empleada suya, jolvídese de eso!, jolvídese de eso! Mami, si no quiere comer que no coma, pero usted no es su empleada" (Mujer y Madre, 60 años. Risaralda).

En estos casos, puede organizarse enfrentamientos entre hijos y padres, lo cual agudiza el evento de crisis familiar. Por ello, algunos integrantes de las familias prefieren mantener en secreto un conflicto relacional para no involucrar a otros, cuando esto puede afectar el vínculo y los lazos afectivos que han caracterizado una relación en la que media mucho afecto y cercanía. Es una forma de mantener cierta homeostasis familiar, lealtades o algún nivel de "tranquilidad" en algunos subsistemas de este grupo. La lealtad entre los integrantes de las familias, en estos casos, hace que las situaciones y relaciones familiares continúen siendo confusas.

\section{Desnaturalización de patrones interactivos}

Un evento asociado a los procesos de crisis no puede verse aislado de las formas relacionales tradicionales co-construidas dentro y fuera de la familia. Generalmente, es lo que hace evidente la existencia de otros problemas que han estado como telón de fondo, y por ello el evento se convierte en lo más percibido por las personas afectadas. En otras palabras, la crisis es como la punta de Iceberg, mientras otros problemas relacionales se mantienen detrás de esta imagen.

En este sentido, el evento crítico contiene aspectos multicausales y multidimensionales a partir de los cuales se sedimenta una plataforma relacional. La función de un evento es poner en evidencia que algo no está bien entre las personas que establecen formas de vínculos tejidos a partir de conflictos que se repiten una y otra vez. En otras palabras, con el tiempo los conflictos tanto en las relaciones familiares como con personas externas a las familias van adquiriendo un carácter natural $\mathrm{y}$, por ello, no es fácil identificar la existencia de un problema que viene en escalada simétrica, tal como muestra en la secuencia de fragmentos del siguiente relato:

a) -Después de la muerte de mi esposo... tuve que separarme de mi hija menor y llevarme a las dos mayores a otra ciudad para trabajar y sostener a sus hijas;

b) -Luego me entero que mi hija menor, en manos de una familia considerada amiga, fue abusada sexualmente por los hombres de la casa;

c) -Mi hija mayor comenzó a robarme, mi hija menor inicia el consumo de marihuana y vive un ciclo de autoagresión (cortarse las manos);

d) -Yo no me di cuenta... Yo la llamaba y ella nunca contó nada (Madre, 50 años; Hija, 17 años, Risaralda).

En estos casos, la aparición de las crisis pone en evidencia otros problemas y, a su vez, rompe un patrón naturalizado que deja entrever otras acciones desconocidas de algunos de los integrantes de la familia. Llegan situaciones sorpresivas que cambian la dinámica del grupo familiar, la percepción de las personas sobre las acciones cotidianas y las relaciones entre quienes son parte del sistema familiar.

En consecuencia, un nuevo contexto relacional es creado por las personas, ante una alarma que ubica a los participantes en una posición diferente a la acostumbrada. A través de él, emergen preocupaciones no previstas y las familias se ven obligadas a buscar estrategias y a utilizar los recursos para definir una salida por doble vía: una frente al evento y otra respecto a la red de problemas asociados. Muy similar a las características asociadas al principio de equifinalidad en el que un estado final no depende sólo de una condición inicial ni en una relación unidireccional de causa - efecto, sino que parte de diferentes condiciones iniciales y por diferentes caminos. A su vez, este estado final es el inicio de múltiples condiciones desde las cuales el sistema afecta y, a su vez, va a ser afectado bajo diferentes condiciones y por vías diferentes (Bertalanffy, 2001). 
Cuando un evento interrumpe un patrón naturalizado, lo que antes no se veía claro comienza a surgir como algo más evidente aunque esté provisto de incertidumbre, dudas y desconfianza entre las personas. En este sentido, surgen preguntas en torno a ¿qué está pasando?, ¿cómo fue que ocurrió?, ¿qué hizo quién?, ¿de dónde viene esta situación? Y, a su vez, expresiones como: "casi me maluqueo", "pensé que era una broma", "eso me dejó impactada", "no podía creer lo que estaba sucediendo", "de un momento a otro resultaron las cosas asi", "yo empecé a darme cuenta de...", "es una cosa dura", "queda uno como impactado", "en la familia eso causó impacto”.

Es tal el impacto de las crisis en el proceso de desnaturalización de patrones relacionales que las personas y familias quedan en un tiempo cotidiano desconcertante. "Si yo viera desde mi ventana unos alrededores nuevos y muy diferentes, en lugar de los que me son familiares desde hace mucho tiempo, si las cosas se comportaran como nunca lo han hecho, tal vez diría algo parecido a "me he vuelto loco"" (Wittgenstein, 2007, p. 105).

Por estas razones, los hablantes hablan de aquello que fue "sorpresivo" o una especie de "aparición no esperada". Estas son expresiones que marcan el punto de quiebre en la vida cotidiana de las personas y, por lo tanto, es un indicador de cambio o transformación de formas de vida y formas relacionales. Desnaturalizar el patrón puede ser favorable al desarrollo de las familias cuando las personas ven en otros no sólo una acción negativa, sino la oportunidad para cambiar retomando lo nuevo que se conoce en la vida y las relaciones de las personas.

\section{Búsqueda de salidas, decisiones y cambios en las familias}

Bajo este panorama de cambios, la crisis es vivida como una amenaza a su estabilidad y seguridad individual, grupal y social. La fuerza emocional y física, implícita en la experiencia de las crisis, cobija pequeños cortos circuitos en la vida de las personas, es decir, irrumpen un ritmo cotidiano que hace parte de una costumbre, norma de convivencia y patrón de interacción. Las crisis familiares están muy cerca de la reorganización y nuevos funcionamientos del sistema familiar, pues paradójicamente son un aporte para la toma de decisiones y para generar estrategias para el cambio en las relaciones familiares. Este cambio familiar lleva a la unión y a nuevos reencuentros que favorecen el reconocimiento de potenciales y recursos en las personas y las familias.

El proceso vivido es concomitante con la resignificación y nueva lectura de lo que para ellos fue real y hoy es parte de su memoria. "La reconstrucción y resignificación de la memoria, es un ejercicio que incluye acciones presentes hacia la construcción de futuros soñados" (Ospina-Ramírez \& Ospina-Alvarado, 2017, p. 182). Por lo tanto, las salidas a las crisis son observadas mediante los cambios narrativos que hacen las personas al momento de reconstruir la trama familiar y el nuevo contexto en el cual la trama es ubicada. En este momento, el significado tanto del proceso como de los integrantes de las familias y sus acciones es diferente respecto al significado otorgado cuando se hablaba del momento en que vivían el evento crítico. Se transforma una forma de percibir, una perspectiva situacional o del acontecimiento.

Para Ricœur hay una tensión entre significación y acontecimiento. El significado va más allá del acontecimiento, pues el primero está referido a "lo dicho", mientras el segundo está asociado a la acción del decir. Lo que narran las personas no es el acontecimiento como tal, sino el significado del acontecimiento como habla (Ricœur, 2008; Corona, 2005). En este sentido, el cambio está en la percepción que toma otro matiz y se ubica en otro contexto $\mathrm{y}$, en este nuevo marco de referencia, lo que la persona narra y expresa son diferentes. De un contexto confrontativo entre las personas que viven la crisis a un contexto de reconocimiento de apoyos y aprendizajes; de un contexto deficitario y negativo a un contexto propositivo con connotaciones positivas y más esperanzadoras.

Madre que enfrenta la enfermedad de su hijo, por una caída en la que se lesiona una de sus rodillas. El sentirse sola detona en relaciones agresivas de ella con su madre y su esposo. 
"Yo creo que eso me sirvió, o sea, esa experiencia que yo tuve, yo creo que me va a servir bastante porque en una situación que a futuro, que me pase algo similar yo la voy a tomar de otra manera, no me voy a deprimir tanto, no con tanto desespero sino que yo voy a pensar: ¡no!, esta situación se superó de esta manera, me toco hacer esto; o sea, tomando esa experiencia que yo viví, las cosas positivas que viví en el momento. Las cosas negativas, de pronto, porque me tomaron como de tan sorpresa, más adelante yo pensaría de pronto que la situación va a ser un poquito más diferente, de otra manera porque ya la he vivido... Entonces, ya de pronto la voy a manejar mejor $y$ más rápido. De pronto, hasta con más madurez" (Madre, 26 años, Neira).

Accidente automovilístico que tuvo madre, hija y nieta, en el que fallece la hija. La madre debe afrontar el dolor de la pérdida, culpas y señalamientos de su yerno, más la separación de su nieta.

"En micasa todos se pusieron en contra de ellos [de la familia del yerno]. Yo veía que, como que el problema era ellos, porque viendo por la situación que yo había pasado y, ellos le decían por culpa del hijo de ellos, y ellos no han tenido ninguna consideración conmigo (...) [Refiriéndose al cambio] hoy también respetan ya como mis ideas y lo que yo diga. Sí ellos ya... ellos ya siempre se miden un poquito porque pues... por lo que pasamos muy dificil para de pronto uno volverse ahora a meter en otro problema ino! Entonces, ya somos como más... más precavidos, sí, ya compartimos más, son muy detallistas conmigo... Que por dura que sea una situación y si uno tiene a Dios en su corazón, tiene que salir adelante porque él todo lo puede. Pues eso aprendí yo" (Madre, 45 años, Manizales).

En este contexto, la expectativa de una salida triunfante está en medio de un juego de tensiones entre las posibilidades $y$ el surgimiento de diversas dificultades. Podría llamarle un juego de azar y de incertidumbres, pues el logro de resultados favorables no es claro porque dependen, por un lado, de las acciones y decisiones entre las personas implicadas en el grupo familiar y, por el otro, de las acciones de la otra parte externa al sistema familiar, importante para la salida del problema. En los casos donde hay amenaza a la salud, la vida, la integridad humana en cualquiera de sus dimensiones, el azar y la incertidumbre son parte de la relación vida-separación-muerte, en medio de la relación amor-protecciónreconocimiento.

Cuando las crisis son creadas en el contexto de las familias $\mathrm{y}$, por ende, las relaciones son cercanas como es el caso de las parejas, padresmadres e hijos, hermanos, se co-construyen diálogos esperanzadores y la tendencia de las personas es a minimizar la situación y aminorar el impacto negativo en el sistema familiar. No obstante, persisten altibajos emocionales, dudas, incertidumbres e inseguridades frente a cada suceso en el que las personas se encuentran involucradas en el evento crítico. En otras palabras, mientras las personas y familias estén en la lucha por el cambio, el beneficio de la duda es uno de los recursos cognitivos y emocionales que emergen. Las decisiones tomadas comienzan a ser el inicio de un nuevo contexto relacional y un cambio en las formas de vida familiar co-construidas hasta el momento.

En cualquiera de los casos, tal como se vio en los 30 testimonios, las salidas de las crisis, las estrategias, los recursos y las posibilidades que crearon las familias trascendieron su contexto familiar. Es decir, los integrantes de las familias no obraron sólo al interior de este sistema, sino que hubo presencia de redes sociales de apoyo, especialmente amigos, compañeros de trabajo, vecinos, empleados, familia extensa, comunidad, grupos religiosos, servicios sociales, de seguridad, practicantes de Desarrollo Familiar y psicólogos.

Las redes mencionadas son buscadas y aprobadas por las familias durante el proceso y a ellas llegaban directamente o por recomendación de alguien cercano. Es una forma de extensión o ampliación de las redes de acuerdo al contexto de la crisis y a los 
detonantes emocionales, cognitivos, biológicos y afectivos que afectan más a un miembro de la familia con relación a los otros.

Por ejemplo, al preguntar por las personas que ayudaron a las salidas de la crisis: "le tengo que agradecer a un compañero, a un socio de la cooperativa", "la señora que trabajaba en casa... Una señora solidaria” (Madre, 50 años, Neira); "[refiriéndose a su otra hija] Todas las noches venían diez, doce compañeros de aquí, compañeros y compañeras... La abrazaban y la quieren mucho. Entonces, ahí yo le veía que ellos le daban ánimo" (Padre, 72 años, Risaralda), "en el jardín nos colaboraron mucho... Recogieron plata y nos la dieron a nosotros" (Madre, 40 años; Padre, 44 años, Manizales); "la gente del barrio nos protegía" (Hija, 22 años, Manizales). En este caso, las redes son co-construidas en el marco de las prácticas dialógicas, códigos de integración, reconocimiento e imaginación. Son procesos dialógicos creativos que van hacia la búsqueda de acciones más liberadoras. Hay aprendizajes, recuperación y crecimiento focalizados hacia tareas vitales personales e interpersonales (Fried-Schnitman, 2010).

La tendencia a la tranquilidady la estabilidad se mantiene viva, para co-construir un nuevo contexto de organización y funcionamiento familiar con el fin de crear otras formas de vida y reconocer las capacidades de ir hacia nuevos horizontes y proyectos tanto personales como familiares. "En aspectos importantes la mayoría de las relaciones tienden hacia pautas estables, y en realidad, es su estabilización lo que nos permite hablar de pautas culturales, instituciones e identidades individuales" (Gergen, 1996, p. 253).

\section{Conclusiones}

Los momentos de crisis movilizan al sistema familiar, a las personas, a las redes sociales y, por lo tanto, a los diversos contextos relacionales que han co-construido las personas $\mathrm{y}$ familias. Pese a que las personas incrementan sus esfuerzos por mantener unido el sistema familiar, la estructura de este sistema es trastocado de manera temporal y otras veces de manera permanente.
Cuando es temporal la fuerza hacia el retorno de las transacciones sociofamiliares y los recursos creados por las personas y familias logran una organización y funcionamiento similar al que tenían antes de la crisis, aunque aparezcan formas relacionales diferentes. Pero, cuando es permanente, el impacto de la crisis modifica la estructura familiar, hay rupturas en las relaciones, en los vínculos afectivos $\mathrm{y}$, a su vez, los procesos de organización y funcionamiento de las familias se tornan diferentes porque el contexto es otro.

El evento crítico puede ser favorable si genera en las personas una oportunidad para el cambio o para favorecer una situación identificada como problema o un obstáculo visto como algo mejor desde donde pueda crearse nuevas oportunidades hacia mundos posibles, más tranquilos, antes no imaginados. Una situación en la que algo es novedoso durante el proceso de afrontamiento de la crisis, reconocido por las personas como una oportunidad desde donde el cambio comenzó a darse. No obstante, la otra cara de la moneda sigue presente. Es decir, una situación percibida como desfavorable en la que se inicia una trayectoria de lucha dolorosa emocional y/o físicamente, con un fuerte desgaste personal y relacional adentro y afuera del ámbito familiar. En ambos casos, las personas se ven ante nuevas condiciones de vida, nuevos contextos de acción y relación, a tal punto que entre las crisis y los cambios emergen, por un lado, expresiones como "mi vida cambió a partir de este momento" y, por el otro, "una nueva vida vamos a comenzar".

Si bien la familia es activa en sus procesos de cambio ante situaciones de crisis, mediante la co-construcción de estrategias, la utilización de recursos, la búsqueda de oportunidades, la interacción con el contexto social ampliado o las redes de apoyo son ventajas comparativas para salir de situaciones que atormentan un fragmento de su vida cotidiana.

En todo caso, entre las crisis y las salidas de ella siempre hay movimientos de acuerdo con las traducciones que cada quien hace de lo que precede, sucede o proviene, sus expectativas que entran en diálogo con las expectativas de otras personas que son interlocutoras válidas al 
momento de tomar decisiones. El lugar al que se llega es una construcción social, una decisión susceptible de ser mantenida o cambiada porque en las familias, y a través de tiempo, queda viva una forma de identidad relacional y vincular.

\section{Lista de referencias}

Anderson, H. (1999). Conversación, lenguaje y posibilidades. Buenos Aires: Amorrortu.

Arfuch, L. (2013). Memoria y autobiografía. Buenos Aires: Fondo de Cultura Económica.

Bajtín, M. (1997). Hacia una filosofía del acto ético. De los borradores y otros escritos. Barcelona: Anthropos.

Bajtín, M. (2000). Yo también soy (fragmentos sobre el otro). México, D. F.: Taurus.

Bajtín, M. (2011). Las fronteras del discurso. Buenos Aires: Las Cuarenta.

Bateson, G. (2006). Una unidad sagrada. Pasos ulteriores hacia una ecología de la mente. Barcelona: Gedisa.

Bertalanffy, L. (2001). Teoría general de los sistemas. México, D. F.: Fondo de Cultura Económica.

Bubnova, T. (2006). Voz, sentido y diálogo en Bajtín. Acta Poética, 27 (1), pp. 1-18.

Corona, P. E. (2005). Paul Ricœur. Lenguaje, texto y realidad. Buenos Aires: Biblos.

Fried-Schnitman, D. (2008). Diálogos generativos. En G. Rodríguez-Fernández (comp.) Diálogos Apreciativos: el socioconstruccionismo en acción, (pp. 1748). Madrid: Oñati-Editorial Dykinson.

Fried-Schnitman, D. (2010). Perspectivas generativas en la gestión de conflictos sociales. Revista de Estudios Sociales, (36), pp. 51-63.

García, R. E. (2012). Diálogo, identidad y discurso en la vida social. Una reflexión sociopsicológica desde el pensamiento de M. Bajtín. Uaricha Revista de Psicología (Nueva época), 9 (18), pp. 38-54.

Gergen, K. J. (1996). Realidades y relaciones. Aproximaciones a la construcción social. Barcelona: Paidós.

Gergen, K. J. (2007). Construccionismo social. Aportes para el debate y la práctica. Bogotá, D. C.: Uniandes.
Hernández, A. (2004). Psicoterapia sistémica breve. La construcción del cambio con individuos, parejas y familias. Bogotá, D. C.: Editorial Códice, ltda.

Ospina-Ramírez, D. A. \& Ospina-Alvarado, M. C. (2017). Futuros posibles, el potencial creativo de niñas y niños para la construcción de paz. Revista Latinoamericana de Ciencias Sociales, Niñez y Juventud, 15 (1), pp. 175-192. Doi :10.11600/1692715x.1511016022016.

Patiño-López, J. A. (2017). Entrevista a la profesora María Hilda Sánchez-Jiménez. Revista Latinoamericana de Ciencias Sociales, niñez y juventud, 15 (1), pp. 618624.

Ricœur, P. (2008). Hermenéutica y acción. Buenos Aires: Prometeo.

Strauss, A. \& Corbin, J. (2002). Bases de la investigación cualitativa. Técnicas y procedimientos para desarrollar la teoría fundamentada. Medellín: Editorial Universidad de Antioquia.

Sánchez-Jiménez,M.H.(2013). Conversaciones terapéuticas que acompañan las transformaciones sociolingüísticas en las relaciones sociofamiliares. Revista Latinoamericana de Estudios de Familia, 5, pp. 160-185.

Sánchez-Jiménez, M. H. (2015). Terapia familiar sistémica-construccionista. Lógicas sociolingüísticas que co-dicen. En D. F. Schnitman (ed.) Dialogues for Transformation: Experiences in Therapy and Other Psycho-social Interventions in Latin America, (pp. 105-127). Chagrin Falls: Taos Institute Publications, WorldShare Books.

Sánchez-Jiménez, M. H. (2016). Movimientos sociolingüísticos en las conversaciones terapéuticas. Hacia los lenguajes del cambio. Manizales: Editorial Universidad de Caldas.

Wittgenstein, L. (2007). Observaciones sobre la filosofía de la psicología, vol. II. México, D. F.: Filosofía Contemporánea. 